\title{
Sovereign recovery schemes: \\ Discounting and risk management issues
}

\author{
First version: 5 January 2012 \\ This version: 10 June 2013 \\ Jean-Paul LAURENT, Joe BonNAUd, Laurent CARLIER, \& Jean-Luc VILA ${ }^{1}$
}

\begin{abstract}
We consider some pricing and risk management issues related to defaultable bonds, in the context of sovereign debt default and restructuring. Standard recovery schemes such as fractional recovery of market value, of Treasury and of face value are investigated: we discuss their consistency with market practice both from a pricing and a risk management perspective. We also pay attention to the tradable basic instruments such as defaultable discount bonds or coupon and principal strips that are the building blocks of traded level coupon bonds. Modelfree pricing formulas are provided and the use of a hypothetical default-free yield curve is challenged. We show that the fractional recovery of par involves two discount curves, one for principal payments and one for coupon payments, a departure from standard bootstrapping and pricing engines. In a second step, this pricing framework can be specialized along the modelling lines routinely used in credit derivatives markets. In light of collective action clauses applicable to the issuance of new bonds in the eurozone and the pricing characteristics of strips, we investigate some practical issues on bond and credit derivatives markets: stripping of bonds in distressed periods, implied market recovery scheme and consistent recovery rates.
\end{abstract}

JEL Classification: G01, G12, G33

Keywords: Default, sovereign bond, coupon strip, principal strip, sovereign CDS, recovery of face value, collective action clause.

1 Joe Bonnaud FIRST, BNP Paribas, 10 Harewood Avenue, London NW1 6AA, UK, joe.bonnaud@uk.bnpparibas.com. Laurent Carlier, FIRST, BNP Paribas, 10 Harewood Avenue, London NW16AA, UK, laurent.carlier@uk.bnpparibas.com. Jean-Paul Laurent is from University Paris 1 Panthéon - Sorbonne, 17, rue de la Sorbonne, 75005, Paris, France, PRISM and Labex ReFi, http://laurent.jeanpaul.free.fr, laurent.jeanpaul@free.fr or jean-paul.laurent@univ-paris1.fr. Jean-Luc Vila, Capula Investment Management LLP, 8 Lancelot Place, London, SW7 1DR, UK, JVila@capulaglobal.com or jean-luc@vilaonline.com. The authors thanks P. Amzelek, F. Ben Atig, G. Butti, L. Cousot, J. Dinh, M. Musiela, M. Rutkowski, A. Wengner and participants of the 2012 AFFI conference in Strasbourg for useful discussions and feedback. Jean-Paul Laurent acknowledges support from the Fixed Income and Research Strategies Team (FIRST) of BNP Paribas and from the BNP Paribas Cardif chair "management de la modélisation". This paper is for academic purpose only, reflects the authors' views only and the authors take the sole responsibility of any errors or misconceptions. In addition, the views expressed here are not necessarily related to the way BNP Paribas or Capula Investment Management LLP manage investments in such instruments. 
The default risk component in government bond prices is a clear matter of concern for academics and practitioners. This papers deals with a relative value / cross sectional approach. For a given issuer and a given point in time, we state the price restrictions among a set a bonds with different maturities and coupon rate. We figure out how recovery schemes, collective action clauses features, prices of coupon and/or principal strips affect the coupon and term structure of bonds prices and question standard discounting methodologies and market practice.

Given new market regulations in the US and in Europe, bond pricing algorithms have become of first importance with respect to market-making or systematic bond trading. Sovereign bond prices act as an anchor in capital markets and properly dealing with increased and volatile default risk is topical.

As can be seen from the 2005 BIS study or the discussion paper from the Bank of Japan (Kikuchin and Shintani [2012]) current methodologies involved in government yield curve estimation and constant maturity Treasury (CMT) rates disclosure are not concerned with the possibility of debt restructurings say. Moreover, constant maturity treasury rates are not market observables but outcomes of smoothing and interpolating that may not properly account for coupon and default risk effects in the first stage.

A related issue is the overreliance of many econometric studies and trading strategies on hypothetical risk-free rates and questionable spread methodologies. Government bonds rates are often used as proxies for such risk-free rates, but this does not address the assessment of default risk in the base curve or the impact of such default risk on the significance of subsequently derived spreads.

The literature on defaultable bonds usually involves specifying an unobserved default-free rate process and on top on that a probabilistic modelling of default arrivals and eventually a recovery mechanism (see Duffie and Singleton [1999]). As further discussed, we can skip the intermediate stage of default-free rate specification and jump directly to defaultable bond price. In that simple approach one deals directly with the building blocks of government bonds, could be principal strips (P-strips) or coupon strips (C-strips) when these are traded and the possible recovery mechanisms.

Specifying the bond payments in case of default is of clear importance. Three important recovery schemes, known as fractional recovery of market value (RMV thereafter, Duffie et al. [1996], Duffie and Singleton [1999] and Collin-Dufresne et al. [2004]), recovery of treasury (RT, Jarrow and Turnbull [1995], Jarrow et al. [1997]) recovery of face value (RFV) ${ }^{2}$ have been widely considered.

Recovery of face value is in line with common bankruptcy procedures and market practice for distressed corporate, emerging markets bonds (Merrick [2001], Andritzky [2005] or Vrugt [2011]) or sovereign CDS. As shown by the Greek bond swap, this is an applicable scheme. In such a framework coupon and principal payments do not have the same rights. Typically, coupons have zero-recovery, while the recovery is concentrated on principal payment which is due at default date (principal acceleration).

\footnotetext{
${ }^{2}$ This approach is often referred to as fractional recovery of par as in Duffie [1998] or as fractional recovery of nominal. Guha [2003], Madan et al. [2006] use the "fractional recovery of face value" terminology. At default time, the claim is based on the nominal value of the bond, irrespectively of the coupon and maturity of the defaulted bond.
} 
Recovery of face value is inconsistent with the use of the same risky discount factors for coupon and principal payments and Z - spread methodologies ("street method"). This point is made clear in Berd, Mashal and Wang [2004a,b] or O'Kane and Sen [2005]). We go here one step beyond by relaxing the usual assumptions regarding constancy of recovery rates or the independence between default arrival and default-free rates.

We can think of other mechanisms such an exit of the eurozone of a sovereign issuer. Since such change of currency involves the same haircut for coupon and principal payments, this leads to risky discount factors that depend only upon maturity ${ }^{3}$.

A specificity of the debt structure of major sovereign issuers is the existence of a market for strips. In some markets, C-strips and P-strips are fungible, say as in the French government bond market, while in others such as the US Treasury market only C-strips are fungible. The model CAC in the eurozone deal with the voting rights of strips and provide interesting information regarding the rights attached to coupon and principal in case of bond restructuring.

The paper is organized as follows: Section 1 recalls the "street approach" to pricing and risk managing defaultable bonds. Section 2 connects the street approach to the modelling of defaults and recovery. Section 3 specifically focuses on fractional recovery of market value scheme, while Section 4 discusses the applicability of the fractional recovery of Treasury method. Section 5 deals with the fractional recovery of par (or face value) approach. Section 6 investigates in greater detail the extra modelling constraints routinely used in credit risk models under the recovery of face value approach. Section 7 briefly addresses alternative recovery schemes and their impact on the relative pricing of coupon and principal payments. Eventually, Section 8 addresses a number of practical and empirical features in connection with collective action clauses and the pricing of principal and coupon strips. The appendix briefly addresses some adaptation of standard mathematical finance tools to relate existence of defaultable discount factors and the absence of arbitrage opportunities.

\section{1) Street method for bond pricing}

Our starting point is a set of traded defaultable bullet bonds issued by a given sovereign. We look for a set of discount factors to be applied to contractual bond cash-flows, consistent with the prices of traded bonds. We are concerned with the relative prices provided by different pricing engines as coupon rate or bond maturity varies. The purpose of this paper is to assess the consequences of recovery mechanisms on bond pricing, especially given that there is not always a clear best choice in the case of sovereign debt default and restructuring ${ }^{4}$.

Further assumptions are made to avoid unnecessary notational burden. We recall that $F$ will denote the face value, $C$ the coupon paid at dates $t_{1}=1, \ldots, t_{n}=n$. We restrict the set of

\footnotetext{
${ }^{3}$ Similarly, a moratorium in which all coupon and principal payments would be delayed would lead to the same risky discount factors to be applied to coupon and principal payments. On the opposite, lengthening of maturities and/or coupon reduction emphasize differences between coupon and principal payments.

${ }^{4}$ While we focus upon standard recovery mechanisms, one could extend the scope of analysis. For instance, the 2003 Uruguay bond swap was associated with a lengthening of bond maturities, the coupon rate of bonds being unchanged.
} 
scheduled coupon payment dates to integers. $c=\frac{C}{F}$ will be the coupon rate. $T=t_{n}=n$ will denote the maturity date of the bond. For simplicity, since we are only concerned with crosssectional approaches, we do not refer to today's date. ${ }^{5}$

Let us emphasize that the above cash-flows are contractual. In case of default, there are to be reduced according to the recovery scheme.

The most commonly applied approach postulates the existence of non negative risky discount factors $B^{*}(i), i=1,2, \ldots$ such that the traded prices of bullet bonds $P_{T}^{*}$ (with corresponding coupons $C_{T}$ ) for maturities $T=1,2, \ldots$ fulfil :

$$
P_{T}^{*}=\sum_{i=1}^{T} C_{T} \times B^{*}(i)+F \times B^{*}(T)
$$

The par rate for maturity $T$ is defined as the coupon rate such $y_{T}^{*}$ that: $F=\sum_{i=1}^{T} y_{T}^{*} F \times B^{*}(i)+F \times B^{*}(T)$. We can thus write the price $P^{*}$ of a hypothetical bond with maturity $T$ and coupon $C$ :

$$
P^{*}=F+\left(C-y_{T}^{*} F\right) \times\left(\sum_{i=1}^{T} B^{*}(i)\right)
$$

or $\frac{P^{*}}{F}=1+\left(\frac{C}{F}-y_{T}^{*}\right) \times\left(\sum_{i=1}^{T} B^{*}(i)\right), \sum_{i=1}^{T} B^{*}(i)$ being the value of a "risky" annuity (or PV01 or risky level depending upon the pricing context) with maturity $T$.

This extends the default-free pricing scheme to defaultable bonds. In the case of default-free bonds, various equivalent mathematical approaches, Farkas lemma, separating hyperplane theorem or Hahn-Banach theorem guarantee the existence of (positive) discount factors given an arbitrage-free set of bonds.

The basic equations $P^{*}=C \times\left(\sum_{i=1}^{T} B^{*}(i)\right)+F \times B^{*}(T)$ can be seen as a linear model involving latent factors $B^{*}(i)$. Only discount factors with maturities corresponding to payment dates are involved.

In the above exposition, the set of payment dates for traded bonds coincides with the set of tenor dates involved in interest rate risk management. In such a case, the $B *(i)$ are uniquely determined from traded prices at a given date ${ }^{6}$.

\footnotetext{
${ }^{5}$ The pricing methodologies studied below can readily be extended to account for a larger set of payment dates (either discrete or continuous tenors) and amortization schemes or step-up coupons at the price of notational burden.

${ }^{6}$ Let us expand briefly about the above setting and calibration issues and consistency with market quotes. Given the simplified yearly time scale and assuming that maturities of traded bonds span that time scale, we can compute the discount factors by solving a triangular system of linear equations. For instance, if we assume that the one year bond is traded (with yearly coupon), we will have directly
} 
This previous approach, based on an analogy with default-free bonds, is consistent with Bloomberg valuation tools (see Ward [2010, 2011] for BVAL or Lee [2007] regarding “fair value market curves") ${ }^{7}$.

To which extent such standard approach can be applied in the context of sovereign financial distress requires further investigation: For instance, the formula $P^{*}=C \times\left(\sum_{i=1}^{T} B^{*}(i)\right)+F \times B^{*}(T)$ is not innocuous. Let us consider two bonds, with same maturity $T$, same face value $F$ and different coupons, $C$ and $C^{\prime}$. Then, their prices will differ by $\left(C^{\prime}-C\right) \times\left(\sum_{i=1}^{T} B^{*}(i)\right)$. The prices will only be equal if $\sum_{i=1}^{T} B^{*}(i)=0$ or equivalently $B *(i)=0$, thus all bond prices should be equal to zero. When looking at Greek bonds on the $23^{\text {rd }}$ of November, 2011, we can notice that two bonds, one with coupon rate equal to $3.7 \%$ maturing on 20/07/2015 and one with coupon rate equal to $6.1 \%$, maturing almost at the same time, on 20/08/2015, have almost the same clean price of $29 \%$ of face value. This provides a clear indication of the difficulties in using without caution risky discount factors in bond pricing. This point has been stressed by Andritzky [2005], distressed bonds being traded on a price basis rather than a spread basis.

\section{2) Connection between the "street approach" and default modelling.}

As can be seen from above, the street approach does not either involve a mere notion of probability, nor any consideration of the recovery mechanism in case of default. However, it is worth wondering whether there is some rationale behind such approach.

To go further in the pricing and risk management analysis, we need a proper description of cash-flows of defaultable bonds. This obviously includes the description of contractual cashflows, coupons and principal in the case where no default or restructuring occurs before

$B^{*}(1)$. We should then be able to compute $B^{*}(2)$ from $B^{*}(1)$ and the price of the two years bond, $P_{2}^{*}=C_{2} \times\left(\sum_{i=1}^{2} B *(i)\right)+F \times B *(2)=C_{2} \times B *(1)+\left(F+C_{2}\right) \times B *(2)$.

It is worth noting that the pricing scheme is "incomplete" since we would only know about the discount factors for tenor dates and we would be unable to price a new bond with payment dates not corresponding to the stated tenor dates. For this purpose, we need a second layer in order to map discount factors with discrete tenors to discount factors with continuous tenor dates: $B^{*}(i)$, $i=1, \ldots, n \rightarrow B^{*}(t), t \geq 0$. Once this interpolation or smoothing procedure has been specified, the pricing scheme for bonds, with non standard maturity and/or coupon payment dates is complete.

${ }^{7}$ Quite often, a "risk-free" set of discount factors $B(i)$ is given. This is to be understood as the discount factor associated with a base curve, usually derived for swap quotes or from a benchmark Treasury curve. Then one can formally introduce a $\mathrm{Z}-$ spread through $B *(i)=B(i) \times S(i)$ and $S(i)=\exp (-i \times z(i))$. We deal here with an extra layer of modelling. Provided that no negative basis effect occurs, $S(i)<1$. However, it may be that the base swap rate curve goes above the studied sovereign curve. Then, $S(i)>1$, and we cannot think of $S$ to be a survival function. 
maturity, but also the recovery payment (or secondary claim) at default, if default occurs before maturity ${ }^{8}$. We will subsequently consider three recovery mechanisms, extensively studied in the academic literature, with well-known pro and cons, namely, fractional recovery of market value, of Treasury and of face value. This is not intended to deal with all practical cases, but provides good benchmarks for further analyses. For simplicity, we will assume that the default date is the same economical and mathematical object, whatever the recovery mechanism and $\tau$ will subsequently denote the default date of the bond(s).

While the benchmark RMV, RT, RFV approaches deal with a single recovery parameter to be applied to all outstanding bonds and loans, market practice may be different. In one of its preliminary stages, the Greek PSI involved a subset of outstanding bonds within a given range of maturities (selective default). Sovereign CDS features such as "Old R", "Mod R", "Mod Mod R" account for such features. Different bonds issued by the same entity, even in the same currency, may not be ruled by the same law. In the eurozone, some bonds are issued under domestic law, others under English law, collective action clauses may apply or not. Pari passu treatment of bond holders and implicit seniority (such as bonds held by ECB) are other issues of importance. We do not deal here with strategic renegotiation. Our main focus is the relative pricing of bonds with different coupons and maturities and there is little literature on that topic, especially in the context of sovereign default. Andritzky [2006] provides a comprehensive review of issues in sovereign bond restructuring. Duffie et al. [2003] illustrate the specificities of sovereign distress focusing on Russian debt, different default treatments leading to possibly different discount factors.

A second step involves identifying relevant building blocks, streams of coupons, defaultable discount bonds ${ }^{9}$, such that already traded bonds or tradable assets that could be obtained from stripping are linear combinations of the building blocks. We will subsequently deal with a frictionless market and thus with linear pricing rules. What is needed is a procedure that allows extracting the prices of the building blocks, consistently with prices of traded and liquid bonds. Pricing formulas are meant as expressions of defaultable bond prices as linear combinations of the prices of the building blocks. Such static decomposition does not require a probabilistic model of default but does depend upon the recovery scheme.

Dynamic models of default provide further structure regarding the pricing of the building blocks. The standard mathematical finance framework associated with reduced-form modelling involves a short-term default-free rate $r$, a default intensity $\lambda^{i}$ and a pricing probability measure $Q^{\text {ii }}$. Some extra technical restrictions are involved in order to have a simple connection with standard discounting techniques ${ }^{\mathrm{iii}}$. It should be made clear that the main results of the paper do not rely upon such modelling assumptions ${ }^{\text {iv }}$.

\section{3) Fractional recovery of market value method}

Fractional recovery of market value method (as well as RT approach) is broadly in line with the $\mathrm{Z}$ - spread methodology provided that we are given a default-free reference curve.

\footnotetext{
${ }^{8}$ Not so long ago, it was a common assumption to neglect the possibility of default in the case of sovereign bonds. For instance, in Elton and Green [1998], the starting point is the statement "cashflows of non-callable treasury securities are fixed and certain, simplifying the pricing of these assets to a present value calculation".

${ }^{9}$ Regarding discount bonds, depending upon the context, we may have to deal with continuous tenors or remain in a discrete tenor setting.
} 
Under the fractional recovery of market value approach, the bond holders receive, at default time, a fraction, equal to the recovery rate $\delta$, of the pre-default market value of the bond. This is thus a recursive approach (see Duffie, Schroder and C. Skiadas (1996)). In many cases $\delta$ is assumed to be a deterministic ${ }^{10}$. Let us remark that the defaultable discount bond prices have a rather tricky pattern since their price is scaled down by $\delta$ at default time. As was mentioned in the introduction, the fractional recovery of market value approach leads to easy to deal with computations, even though its economic significance and practical use have been questioned. Under the fractional recovery of market value approach, defaultable bonds can actually be seen as portfolios of defaultable discount bonds, which will be the basic tradable instruments.

The usual outcome of the above stochastic model of default and recovery is the writing of risky discount factors as: $B^{*}(i)=E^{Q}\left[\exp \left(-\int_{0}^{i}(r(s)+\lambda(s) \times(1-\delta)) d s\right)\right]$.

It is worth noting that these discount factors are the pre-default prices of defaultable discount bonds with the same fractional recovery of market value mechanism as level coupon bonds.

The building of defaultable discount bonds and thus their pricing from level coupon bonds is straightforward. Let us go back to cash-flow analyses and the example depicted above. We are given a zero coupon defaultable bond scheduled to mature in one year, and a two years defaultable level coupon bond with coupon $C_{2}$. It can readily be seen that holding the previous level coupon bond and being short $C_{2}$ units of one year defaultable bond (with face value being equal to 1 ) synthesizes a two year defaultable discount bond (with face value $F+C_{2}$ ) and the same fractional recovery of market value mechanism at default as the two constituent traded bonds. In the depicted static replication procedure, only defaultable bonds are involved and there is no need for default-free bonds to be traded. Thus, the discount factors $B^{*}(i)$ do correspond to prices of defaultable discount bonds and their prices can be computed from traded level coupon bonds in an algebraic way.

We could think of defining zero-recovery discount bonds with prices provided by $E^{Q}\left[\exp \left(-\int_{0}^{i}(r(s)+\lambda(s)) d s\right)\right]$. However, such zero-recovery bonds as well as default free bonds with prices provided by $E^{Q}\left[\exp \left(-\int_{0}^{i} r(s) d s\right)\right]$ are abstract claims that cannot be synthetized from traded defaultable bonds and are not required in a defaultable bond pricing context.

\section{4) Fractional recovery of Treasury method.}

This recovery mechanism corresponds to a proportional haircut applied to all cash-flows after default. The bond cash-flows are scaled by $\delta$, which is the recovery rate. We can then depict

\footnotetext{
${ }^{10}$ See Merrick [2001], Madan et al. [2006], Pan and Singleton [2008], Das and Hanouna [2009] for a relaxation of this constraint in a pricing framework.
} 
the effective cash-flows on a given defaultable bond as: $F_{i} 1_{\tau>i}+\delta F_{i} 1_{\tau \leq i}$, where $F_{i}=C$ for $i=1, \ldots, n-1$ and $F_{T}=F+C$. The recovery rate needs to be actually known before the scheduled payment date following default, for the cash-flows to be sensibly defined. Thus, recovery rate neither needs to be known at pricing time nor to be given a specific probability distribution. This scaling of cash-flows can be applied to a subset of issued bonds if we want to cope with selective defaults.

RT approach can be considered as a recovery on cash-flows: Up to default time, the scheduled cash-flows are being paid while at default time, a proportional haircut is applied on all postdefault payments, coupon or principal payments ${ }^{11}$.

Regarding sovereign default, that recovery mechanism can be associated with a forced conversion of bonds issued, say in euros, to a new domestic currency, $\delta$ being thus the exchange rate at the time of the forced exchange.

The cash-flows of coupon bonds can be seen as linear combinations of elementary cash-flows of the form $1_{\tau>i}+\delta 1_{\tau \leq i}$ paid at dates $i=1, \ldots, n$.

Conversely, let us go back once again to the two years level coupon bond example. It can be seen that the two year defaultable discount bond, paying $1_{\tau>2}+\delta 1_{\tau \leq 2}$ can be synthesized exactly the same way as in the fractional recovery of market value. Thus, in the fractional recovery of cash-flows, the discount factors $B^{*}(i)$ also correspond to prices of defaultable discount bonds and their prices can be computed from traded level coupon bonds in an algebraic way. As in the recovery of market value approach, the replication only involves defaultable bonds and no default-free bonds need to be involved. However, it must be understood that, even though we use the same terminology "defaultable discount bond", we do not speak of the same assets in the recovery of market value and in the recovery of cashflow cases: the cash-flows of discount bonds and associate price processes do not coincide.

We have been able to give the basic equation $P^{*}=C \times\left(\sum_{i=1}^{T} B^{*}(i)\right)+F \times B^{*}(T)$ some economic content and to relate the defaultable discount factors to the prices of some welldefined defaultable discount bonds.

The above fractional recovery of cash-flows is also known as fractional recovery of treasury and has been considered by Jarrow and Turnbull [1995] or Jarrow et al. [1997] among others: Instead of receiving $\delta$ at scheduled payment date in case of default, we could think of receiving $\delta$ times a discounting factor between scheduled payment date and default date. This defines an equivalent recovery scheme with a cash payment at default date. In the quoted papers, the applicable discount rate is a deemed risk-free Treasury rate. But it can be seen that any discounting scheme between scheduled payment dates and default date leads to a valid recovery mechanism. For instance, one could use some suitable post-default risky discount rates to account for the possibility of a second default.

\footnotetext{
${ }^{11}$ In the fractional recovery of Treasury, the bondholders receive a fraction of the present value of the post-default cash-flows where the discount rates are derived from a Treasury curve. This is equivalent to fractional recovery of cash-flows provided that Treasury is default-free. Duffie et al. (1996) use the terminology "fractional recovery of a default-free version of the same security".
} 
The collective action clauses applicable to news bonds issued after January 2013 in the eurozone paves the way for such a mechanism ${ }^{12}$. It defines the voting rights attached to strips of government bonds. This corresponds to a recovery of cash-flows scheme where the discount rate between the scheduled maturity date and default date depends upon the coupon rate structure at default time. As a consequence, principal and coupon strips have the same voting rights, their defaulted value is likely to the same. This is a necessity when strips are fungible and may be seen as a desirable property (from issuer's perspective) when there are not.

With fungible P-strips and C-strips, level coupon bonds are linear combination of clearly identified defaultable discount bonds. If we look at the model CAC in the eurozone, the applicable discount rates between scheduled payment dates and default date are not known from inception and depend upon the scheduled payment date. However, the connection between bond and defaultable strips prices remains $P^{*}=C \times\left(\sum_{i=1}^{T} B^{*}(i)\right)+F \times B^{*}(T)$. As for the recovery of market value case, we do not need to bother about default-free discount rates.

One can think of writing the defaultable cash-flows $F_{i} 1_{\tau>i}+\delta F_{i} 1_{\tau \leq i}$ as $\delta F_{i}+(1-\delta) F_{i} 1_{\tau>i}$, $i=1, \ldots, n$. If the recovery parameter is known for inception, which is more of a simplifying modelling assumption than financial reasoning, the payment $\delta F_{i}$ can be seen as certain. The cash-flows of the defaultable bond as $\delta F_{i}+(1-\delta) F_{i} 1_{\tau>i}, i=1, \ldots, n$, can be split into two streams, one which is default free, while the other one involves defaultable cash-flows $(1-\delta) F_{i}$ with zero recovery. This decomposition and subsequent pricing formulas are quite artificial since they involve default-free and zero recovery defaultable bonds which are not traded.

Fortunately enough, we found two mechanisms, recovery of market value and of cash-flows leading to discounting contractual bond cash-flows with a single set of risky discount factors as commonly done under market practice : $P^{*}=C \times\left(\sum_{i=1}^{T} B^{*}(i)\right)+F \times B^{*}(T)$. The building blocks of bullet bonds are defaultable discount bonds (or strips) in the two cases.

Relating recovery of Treasury to the exit of the eurozone of a core country is not incidental. It corresponds to a shift of the exchange rate in a fixed rate regime. If the numéraire corresponds to the strong currency (or foreign currency or central bank currency whenever central bank is independent from defaulted entity), bond holders will suffer a loss. However, if the numéraire is "government money", the discount bond components are default-free. It is thus not surprising that the default-free pricing framework can be readily translated ${ }^{13}$.

\footnotetext{
${ }^{12}$ We refer to the survey paper of Committeri and Spadafora [2013] and the references therein about the legal and economic context and the impact of such collective action clauses on bond pricing.

${ }^{13}$ Thinking in terms of "government money" may first look as a mathematical finance oddity. We may argue that it is not. Repudiation of debt say, can be associated with a strong tax relief for domestic investors. On the other hand, there are cases where no formal default occurs, but since exchange rate decreases, non domestic investors will suffer from losses.
} 


\section{5) Fractional recovery of face value.}

This approach is standard for corporate or emerging markets issuers. We show that in such a recovery scheme, absence of arbitrage across bonds leads to two distinct discount curves associated with non fungible basic building blocks. Therefore, P-strips and C-strips are quite unrelated financial objects, with the only constraint that a P-strip has a higher price than a Cstrip.

In the fractional recovery of face value approach, the bond holder receives $\delta \times F$ at default time $\tau$, i.e. a fraction of the face value ${ }^{14}$. This is the standard approach involved in emerging bond markets (Merrick [2001], Andritzky [2005] or Vrugt [2011]) or CDS pricing (Pan and Singleton [2008], Longstaff et al. [2011]). Claiming the principal payment at default date and not maturity date, known as principal acceleration can be profitable when dealing with long outstanding maturity bonds. On the other hand, there is no claim on the coupons, thus they are associated with a zero-recovery. It is clear that claims on coupon and principal payments are not the same, thus paving the way to different discount rates.

Though dedicated to corporate bonds, the seminal paper of Duffie and Singleton [1999] provides quite useful results when considering sovereign bond pricing. As is apparent from pricing equations (25) and (26) comparing RMV (Recovery of Market Value) and RFV (recovery of face value), defaultable discount factors are being introduced, involving a unique curve in case of RMV and two distinct curves for RFV ${ }^{15}$. Equation (25) shows that the decomposition between default-free rates and default component is not required to derive a discounting formula relating bond cash-flows and prices. Thus, the stated formulas also apply to defaultable Treasuries and the hypothetical unobservable default-free short term rate fortunately cancels out of the valuation formula. The same line of reasoning is applicable in the recovery of face value mechanism.

In the recovery of face value approach, a defaultable bond can be decomposed into a risky annuity with zero-recovery (the coupon stream) and a defaultable principal payment. The latter component is a distinct payoff that cannot be synthetized from defaultable discount bonds with predetermined payment date and zero-recovery. Provided that we deal with a set a coupon bonds, we can think of further stripping the risky annuity in defaultable discount bonds with zero recovery maturing at coupon payment dates.

In the RFV framework, P-strips and C-strips are quite different assets. A P-strip can be seen a as a coupon strip (defaultable discount bond with zero-recovery) and on top of this a payment $\delta$ at default time $\tau$ provided that $\tau$ is before maturity date $T$. Provided that $\delta>0$, a P-strip is more valuable than a coupon strip if we remain in a RFV framework.

Given these preliminary remarks, let us go back to a more formal approach and denote by $\hat{B}(T)$ today's price of a contract paying the recovery rate $\delta$ on the defaultable bonds, at default time $\tau$, provided that $\tau$ is smaller that $T=n$. Then, the price of the bond can be written as:

\footnotetext{
${ }^{14}$ For simplicity, we will not account for the promised running coupon. The subsequent stripping procedure between coupon and principal payments obviously still holds without that assumption.

${ }^{15}$ See also Duffie [1998], Finkelstein [1999], Guha [2003], Berd [2011].
} 


$$
P=\sum_{i=1}^{n} C \times B^{C}(i)+F \times\left(B^{C}(n)+\hat{B}(n)\right)
$$

Where $B^{C}(i)$ is the price of a coupon strip maturing at date $i$. The price of the principal strip is given by $B^{P}(n)=B^{C}(n)+\hat{B}(n)>B^{C}(n)$. The discount factors related to principal payments are always higher than the discount factors applicable to coupon payments ${ }^{16}$. The coupons are priced with a zero-recovery assumption. The pricing formula:

$$
P=\sum_{i=1}^{n} C \times B^{C}(i)+F \times B^{P}(n)
$$

is related to the structure of default payments and should not be confused with tax effects which are, for instance, discussed in McCulloch [1975] or Elton and Green [1998]. Since $B^{C}(i)<B^{P}(i)$, it seems inconsistent with the linearity of the pricing rule. Actually, it is not. Linearity is still valid when applied to actual cash-flows received by bond holders. It is only the use of contractual coupon and principal payments in the pricing formula that lead to this seemingly inconsistency.

As was done for the two former recovery mechanisms, let us consider the calibration to traded level coupon bonds. Let us consider two one year maturity defaultable bonds, with face value $F$, one with coupon $C$ and the other with coupon $C^{\prime} \neq C$, with respective prices $P$ and $P^{\prime}$. Being long the first bond and short the second one, creates an exposure to coupon payment only and $B^{C}(1)=\frac{P^{\prime}-P}{C^{\prime}-C}$, i.e. the increase rate in bond prices of given maturity with coupon rate. Using the same procedure with two year level coupon bonds allows to synthesize a two year IO and derive $B^{C}(2)$. Given the prices of coupon strips and the prices of level coupon bonds, we readily synthesize and price a principal strip. Clearly, the calibration is more involved since two sets of level coupon bonds with different coupon rates are required. As for the two former recovery mechanisms, the bootstrap calibration procedure makes clear the constituents of defaultable level coupon bonds.

Let us further investigate the pricing formula associated with the recovery of face value approach. The par rate $y_{T}$ is the coupon rate such that $F=\sum_{i=1}^{T} y_{T} F \times B^{C}(i)+F \times B^{P}(T)$. By combining the equation providing $P$ and the definition of the par rate $y_{T}$, we obtain:

$$
P=F+\left(C-y_{T} F\right) \times\left(\sum_{i=1}^{T} B^{C}(i)\right)
$$

or equivalently:

$$
\frac{P}{F}=1+\left(c-y_{T}\right) \times\left(\sum_{i=1}^{T} B^{C}(i)\right)
$$

which is to be compared with the pricing formulas associated with the recovery of market value and the recovery of Treasury approaches: $\frac{P^{*}}{F}=1+\left(c-y_{T}^{*}\right) \times\left(\sum_{i=1}^{T} B^{*}(i)\right)$. At origination, i.e. if a par bond is actually traded for this maturity, the par rate becomes a market observable for that maturity, denoted by $y_{T}$. In that case, calibration of models imply that $y_{T}^{*}=y_{T}$. We

${ }^{16} \hat{B}(0, t)>0$ is the price associated with a positive cash-flow. 
can then study the effect of a change of coupon rate on the prices for maturity $T$ : $\frac{P^{*}}{F}=1+\left(c-y_{T}\right) \times\left(\sum_{i=1}^{T} B^{*}(i)\right)$ and $\frac{P}{F}=1+\left(c-y_{T}\right) \times\left(\sum_{i=1}^{T} B^{C}(i)\right)$. These pricing formulas are quite simple and readily extend the well-known swap formulas. They only differ from one to another by the expression of the "risky level", i.e. the price of defaultable annuity of maturity $T$. For instance, $\sum_{i=1}^{T} B^{C}(i)$ is the price of a zero-recovery risky level annuity associated with the bond market ${ }^{17}$.

\section{6) One modelling step further: the standard credit world approach}

Emerging bond and credit default swap models often involve an extra layer of assumptions. Fortunately enough, it is worth noting that the main results of the paper do not depend upon these arbitrary and stringent assumptions.

To avoid the computational burden of estimating two loosely related discount rate structures, the following procedure can be used. It relies on a number of extra assumptions: constancy of the recovery rate $\delta$, existence of a given default-free base term structure of rates, independence between default date and these default-free rates under the pricing measure $Q$. This is the privileged approach for the pricing of sovereign CDS, both in the academic, as illustrated by Pan and Singleton [2008], Longstaff, Pan, Pedersen and Singleton [2011] and practitioners' worlds (see Finkelstein [1999], Berd, Mashal and Wang [2004a, 2004b] ${ }^{18}$.

Let us denote by $S(i)=Q(\tau>i)$ the (risk-neutral) survival probabilities and $B(i)$ the default-free discount factor for maturity $t$. Then, $B^{C}(i)=B(i) \times S(i)$.

As for the default payment, we need to compute:

$$
\hat{B}(n)=E^{Q}\left[\delta \times F B(\tau) 1_{\tau \leq n}\right]=-\delta \times F \int_{0}^{n} B(t) d S(t)
$$

neglecting the price impact of the recovery on the running coupon. As previously, the price of the principal strip is given by $B^{P}(n)=B^{C}(n)+\hat{B}(n)=B^{C}(n)$ and the level coupon bond prices by $P=\sum_{i=1}^{n} C \times B^{C}(i)+F \times B^{P}(n)$.

Given $\delta$ and the default-free discount factors $S(t)$, only a set of default probabilities needs to be calibrated, from which we derive a parametric expression for coupon and principal strips.

We show below the outcome of such a procedure, given a calibration recovery rate of $40 \%$. The data is based on Italian government prices as in February 2013.

\footnotetext{
${ }^{17}$ This will usually differ from the risky level involved in credit default swap pricing since, for instance, CDS and bond default dates may differ.

${ }^{18}$ Bloomberg also uses such a recovery of face value framework for the valuation of structured notes (Stein [2012]). Given that credit quality of structured notes may be better than that of distressed sovereign bonds, this shows that there is not a unique treatment of default and recovery in the practitioner's world. Thus, the need of deeper investigation.
} 


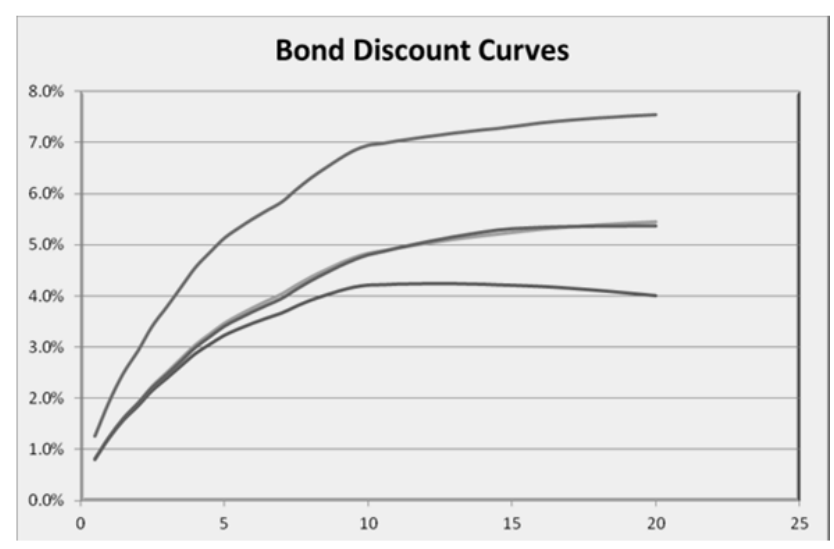

Figure 1: Theoretical discount rates, Italian debt

Upper curve: coupon discount rates, lower curve: principal discount rates, intermediate curve: recovery of treasury

The upper curve is associated with the applicable discount rates for coupon payments, while the lower one deals with principal payments. The intermediate curve results from the recovery of Treasury assumption where coupon and principal payments are discounted at the same rate. This illustrative graph is intended to show the huge discrepancies between the different discount rates. Let us also remark that the intermediate discount curve also corresponds to a RFV scheme with a zero-recovery assumption. Moving away from the rather arbitrary $40 \%$ standard induces huge effects on discount rates.

\section{7) Other recovery schemes}

Given that sovereign default is often associated with forced restructuring, we may think of a number of alternative recovery schemes. Coupon reduction, possibly associated with a lengthening of bond maturity is a possibility. It can be seen that the stream of coupons and the principal payment deserve separate treatments and that we also end-up with two discounting curves. Splitting coupon bonds into C-Strips and P-Strips remains a valid approach. With a coupon reduction, we would have a non-zero recovery on the stream of coupons. Lengthening maturities is opposed to principal acceleration, as in fractional recovery of face value, but on the other hand, we not have a scheduled cut-off of principal payment.

The structural models of François et al. [2011] or Jeanneret [2012] only involve a defaultable consol. This rules-out the practical issues of term and coupon structure modelling. In case of default, a coupon reduction is involved and one does not need to consider principal payments. For perpetual debt, fractional recovery of face and of Treasury approaches coincide.

Clearly, there are a number of possibilities regarding sovereign debt restructuring. One could think of applying a random thinning procedure to allow for different recovery schemes. This would not change the main insights: in most cases, separate treatment of coupon and principal payments are required, leading to two discount curves. A single discount curve would only be got in special cases such as debt repudiation or change of currency.

\section{8) Empirical features}

The recovery scheme and debt restructuring of a major issuer is not a contractual feature. We are faced with two different approaches with their own theoretical merits. In both cases, $\mathrm{P}$ strips and $\mathrm{C}$ strips are the building blocks of defaultable bonds. 
In the fractional recovery of cash-flows, $\mathrm{P}$ strips and $\mathrm{C}$ strips have the same rights and lead to the same value, while $\mathrm{P}$ strips have greater value in the recovery of face value mechanism. The relative pricing issue of $\mathrm{P}$-strips and $\mathrm{C}$-strips with same payment date has been addressed by Daves and Ehrhardt [1993], who argue that P-strips should actually be traded at higher prices than corresponding C-Strips. Jordan et al. [2000] find mixed evidence: P-Strips were usually more expensive that C-Strips, but occasionally the price hierarchy may go the other way round. Based on data collected between 2002 and 2008, Vonhoff [2000] gets some results that go in the same lines as previous studies. For 10 maturities, yields of P-Strips are approximately 10 bps above those of the C-Strips counterparts.

Huij et al. [2010], Vonhoff [2010] focus on principal and coupon strips from 2002 to 2007 for French, German, Spanish and Italian Treasuries. Consistently with previous studies, they find that principal strips sell for higher prices than coupon strips between 85 and 98 percent of the time. The price differences tend to increase with maturity, consistently with the recovery of face value framework. However, as in earlier studies, the magnitude of discrepancies is small.

In the US, P strips and C strips are not fungible are dealt as separate securities, even if the scheduled payment date is the same. This may be due partly to tax effects, not considered in the paper, but reflects a common view that there is something different between coupon and principal payments. On the contrary, from French government debt $\mathrm{P}$ strips and $\mathrm{C}$ strips are fungible. In such a case, there is a unique ISIN number. One cannot trace back whether a principal or coupon payment has been stripped and there is a unique price by necessity. Even in the non fungible case, the price discrepancies between $\mathrm{P}$ strips and $\mathrm{C}$ strips remain small and are much more likely to be related to market frictions rather than different expectations regarding payoffs.

Figure 2 below is a worst case example, based on US Treasury strips maturing on 15 February 2031. Both principal and coupon strips are traded and the discrepancy between prices is magnified for that maturity. The graph shows the historical differences between yields over a five year period (from February 2008 to February 2013). This shows a cap between coupon and principal strips yields at around $10 \mathrm{bps}$. This is not insignificant, but still many orders of magnitude below what one would expect under the RFV scheme (see Italian bond case).

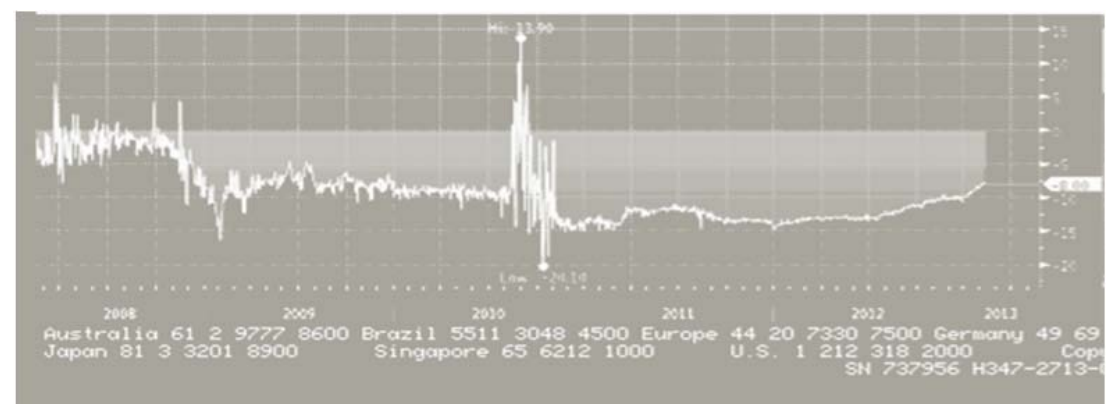

Figure 2: Discrepancies between principal and coupon strips - US Treasuries

In the Greek bond swap, nominal values, irrespective of coupon and maturity have also been used, consistently with the recovery of face value approach and the market pricing practices regarding distressed bonds. Table 1 below provides Greek bond prices shortly prior to the bond restructuring. It can be seen that all prices are quite close to $\delta=22 \%$. Actually, the final price in the CDS auction was $21.5 \%$ with little discrepancy between auctionners (Table 2). 


\begin{tabular}{|c|c|c|}
\hline Irade Maturity Date & Close & live \\
\hline $20 / 03 / 2012$ & 41.00 & 35.25 \\
\hline $18 / 05 / 2012$ & 32.00 & 30.00 \\
\hline $20 / 08 / 2012$ & 28.00 & 26.00 \\
\hline $20 / 05 / 2013$ & 26.50 & 24.50 \\
\hline $20 / 08 / 2013$ & 25.00 & 24.00 \\
\hline $11 / 01 / 2014$ & 26.00 & 24.00 \\
\hline $20 / 05 / 2014$ & 23.00 & 22.00 \\
\hline $20 / 08 / 2014$ & 23.00 & 22.00 \\
\hline $20 / 07 / 2015$ & 24.00 & 22.00 \\
\hline $20 / 08 / 2015$ & 23.00 & 22.00 \\
\hline $20 / 07 / 2016$ & 23.00 & 22.00 \\
\hline $20 / 04 / 2017$ & 23.00 & 22.00 \\
\hline $20 / 07 / 2017$ & 23.00 & 22.00 \\
\hline $20 / 07 / 2018$ & 23.00 & 22.00 \\
\hline $19 / 07 / 2019$ & 23.00 & 22.00 \\
\hline $22 / 10 / 2019$ & 23.00 & 22.00 \\
\hline $19 / 06 / 2020$ & 23.75 & 24.00 \\
\hline $22 / 10 / 2022$ & 22.50 & 22.50 \\
\hline $20 / 03 / 2024$ & 22.00 & 22.00 \\
\hline $25 / 07 / 2025$ & 22.00 & 21.00 \\
\hline $20 / 03 / 2026$ & 22.00 & 22.00 \\
\hline $25 / 07 / 2030$ & 21.25 & 21.00 \\
\hline $20 / 09 / 2037$ & 22.00 & 22.00 \\
\hline $20 / 09 / 2040$ & 22.00 & 22.00 \\
\hline & & \\
\hline & &
\end{tabular}

Table 1: Price structure of Greek government bonds shortly prior to bond restructuring

\begin{tabular}{|l|l|l|l|}
\hline Dealer & Bid & Offer & Dealer \\
\hline Bank of America N.A. & 21.625 & 23.625 & Bank of America N.A. \\
\hline Barclays Bank PLC & 21.0 & 23.0 & Barclays Bank PLC \\
\hline BNP Paribas & 20.75 & 22.75 & BNP Paribas \\
\hline Citigroup Global Markets Limited & 20.5 & 22.5 & Citigroup Global Markets Limited \\
\hline Credit Suisse International & 20.25 & 22.25 & Credit Suisse International \\
\hline Deutsche Bank AG & 20.25 & 22.25 & Deutsche Bank AG \\
\hline Goldman Sachs International & 21.125 & 23.125 & Goldman Sachs International \\
\hline HSBC Bank PLC & 20.25 & 22.25 & HSBC Bank PLC \\
\hline JPMorgan Chase Bank N.A. & 21.25 & 23.25 & JPMorgan Chase Bank N.A. \\
\hline Morgan Stanley \& Co. International PLC & 21.0 & 23.0 & Morgan Stanley \& Co. International PLC \\
\hline Nomura International PLC & 20.0 & 22.0 & Nomura International PLC \\
\hline Société Générale & 21.0 & 23.0 & Société Générale \\
\hline The Royal Bank of Scotland PLC & 22.0 & 24.0 & The Royal Bank of Scotland PLC \\
\hline UBS AG & 20.5 & 22.5 & UBS AG \\
\hline
\end{tabular}

Table 2: Hellenic Republic CDS auction, 19 March 2012

\begin{tabular}{|c|c|c|}
\hline Bloomberg Name & FRTR 8.5 10/19 & FRIR 3.75 25/10/19 \\
\hline Bond Type Name & France Govt & France Govt \\
\hline Coupon & $\mathbf{8 . 5}$ & $\mathbf{3 . 7 5}$ \\
\hline Coupon Length & 12 & 12 \\
\hline Issue Date & 25 -Jan-89 & $07-$ Jul-09 \\
\hline First Settlement Date & 25 -Jan-89 & $07-$ Jul-09 \\
\hline Pirst Coupon Date & $25-$ Oct-89 & $25-$ Oct-09 \\
\hline Vaturity & $25-$ Oct-19 & $25-$ Oct-19 \\
\hline Issuc Price & 95.8 & 99.37 \\
\hline Callable & FALSE & FALSE \\
\hline OutstandingAmount & 8844392893 & 28078000000 \\
\hline ISIN & FR0000570921 & FR0010776161 \\
\hline Par Valuc & 100 & 100 \\
\hline Issuer Location & PAR & PAR \\
\hline DCB Eligibility & TRUE & TRUE \\
\hline DB Currency & EUR & EUR \\
\hline
\end{tabular}

Table 3: OAT features

The analysis of the model CAC in the eurozone provides some further insights. The model CAC states the voting rights of the different debt holders and these are to be considered as the basis for claims in case of debt restructuring. The CAC suggest two distinct treatments for strips and level coupon bonds in case of default. As for level coupon bonds, the nominal value of the bond is taken into account, irrespective of the coupon rate. 
Let us consider the two French government bonds, depicted in Table 3. They share the same schedule of payment dates, have the same voting rights and are thus likely to have the same market value, would a restructuring occur. This is consistent with the recovery of face value approach.

One can also consider the stripped payments of these coupon bonds. As already mentioned, principal and coupon strips being fungible, have the same rights. This is consistent with the recovery of Treasury approach. More specifically, the voting rights of a strip with given maturity are computed by discounting the contractual payment between maturity and default date at a nominal rate based upon the coupon rate structure. Let us denote by $B_{N}(i)$ the nominal discount factor between payment date $i$ and default date. We denote by $C_{2}=8.5 \%$ the high coupon rate and by $C_{1}=3.75 \%$, the small coupon rate. Face values of the two coupon bonds are equal to $1 €$. Thus, the voting rights of the stream of payments associated with the two level coupon bonds are $\sum_{i=1}^{n} C_{2} \times B_{N}(i)+B_{N}(n)$ and $\sum_{i=1}^{n} C_{1} \times B_{N}(i)+B_{N}(n)$. For those to be equal, we must have $\sum_{i=1}^{n} B_{N}(i)=0$, thus $B_{N}(i)=0$ for all payment dates. This contradicts the discounting rule aimed at computing nominal values of strips. Since the nominal values of the two above bonds cannot be equal, they cannot be equal to par altogether. Actually, given the eurozone model CAC rules, none of them will be equal to par.

As a consequence, the holders of the level coupon bond and of the streams of strips with the same scheduled payments will not have the same voting rights. If we think of level coupon bonds and strips are separate securities, this would not breach the equality principle of debt holders.

Also, it would be unlikely on financial and legal point of view that level coupon bonds could be stripped or that they could be reconstituted from strips around a restructuring date. If market for strips and level coupon bonds are being segmented at critical times, then one cannot arbitrage between the former and the latter.

This shows as usual some distance between pricing theory in frictionless markets and market data. Focusing on US Treasuries, Daves and Ehrhardt [1993] or Grinblatt and Longstaff [2000] report that the arbitrage restrictions between C-Strips, P-Strips and underlying bonds are met in the market, while Jordan et al. [2000] stress the difficulty of dealing with synchronous prices when assessing such arbitrage restrictions and report some small but significant discrepancies. Let us stress that such studies were conducted in normal times.

\section{Conclusion}

Simple and standard discounting approaches to defaultable level coupon bonds can be made consistent with standard recovery mechanisms such as recovery of market value or recovery of cash-flows (or equivalently in our framework, recovery of Treasury). More precisely, the defaultable discount factors can be seen as the prices of defaultable discount bonds with positive recovery ${ }^{19}$. Such defaultable discount bonds can be obtained by static replication

\footnotetext{
${ }^{19}$ Defaultable discount bonds with zero recovery are not a straightforward outcome as is the case under the recovery of face value framework.
} 
from traded defaultable level bonds. No default-free bond is required in such analysis, which is good news given the difficulty of stating what should be a default-free discount curve. No assumption about recovery rates or about independence between default date and default-free rates is required for the discounting scheme to apply.

Unfortunately, the recovery of face value is inconsistent with the assumption of a unique discounting curve. One has to consider principal and coupon payments separately. As for the recovery of cash-flows, no assumption about recovery rates, default dates, default-free rates is required for the pricing scheme to apply. The bond building blocks involve defaultable discount bonds with zero-recovery on one hand and a specific instrument associated with payment of recovery at default time. This leads to different calibration approaches from level coupon bonds. When considering corporate bonds, Duffie and Singleton [1999] argue that discrepancies between approaches involving a unique and two discount curves are of small magnitude. Obviously, this has to be mitigated with the current level of yields, bond maturity, discrepancies between coupon rates of issued debt. As illustrated with some European government debts, the magnitude of coupon and principal discount rate might be quite large. Though the recovery of face value approach is standard for corporate, emerging markets bonds and sovereign CDS, it is inconsistent with the fungibility of principal and coupon strips, a common feature among major issuers.

A lot of attention has been put on connections between sovereign CDS and bond markets. While the bond market mainly relies on the assumption of a single discounting curve, the CDS market goes the other way round. Moreover, the choice of the recovery parameter is not innocuous. Eventually, the new collective action clauses applicable to government bonds in the eurozone and the existence of strippable securities are altogether challenging regarding the pricing of sovereign CDS.

Treasury markets are of first importance and have a pivotal role in the computation of corporate or emerging markets bond spreads. Properly dealing with Treasury yield curve is not straightforward due to the uncertainty about recovery schemes. It may also imply a comprehensive upgrade of pricing and risk management tools across many fixed-income instruments: the significance of $\mathrm{Z}$ - spreads or constant maturity treasury rates is questioned.

\section{References}

1) Andritzky, J. R., 2005, Default and recovery rates of sovereign bonds: A case study of the Argentine crisis, The Journal of Fixed Income, Volume 15 (2), 97-108.

2) Andritzky, J. R., Sovereign default risk valuation, implications of debt crises and bond restructurings, Lecture Notes in Economics and Mathematical Systems 582, Springer, 2006.

3) Ang, A., and F. Longstaff, 2011, Systemic sovereign credit risk: Lessons from the US and Europe, NBER discussion paper 16983.

4) Berd, A., 2011, A Guide to modeling credit term structures, in The Oxford Handbook of Credit Derivatives, A. Lipton \& A. Rennie eds, 66-122, Oxford University Press.

5) Bielecki, T. R. and M. Rutkowski, Credit risk: Modeling, valuation and hedging, Springer, 2010, softcover reprint of hardcover 1st ed. 2002.

6) Bielecki, T. R., M. Jeanblanc and M. Rutkowski, Modeling and valuation of credit risk, in 'Stochastic methods in Finance', Lecture Notes in Mathematics, Volume 1856, 27-126, Springer, 2004. 
7) Bank for International Settlements, Zero-coupon Yield Curves: Technical documentation, BIS paper No.25, 2005

8) Berd, A., R. Mashal and P. Wang, 2004a, Defining, estimating and using credit term structures. Part 1: Consistent valuation measures, working paper, Lehman Brothers.

9) Berd, A., R. Mashal and P. Wang, 2004b, Defining, estimating and using credit term structures. Part 3: Consistent CDS-Bond Basis, working paper, Lehman Brothers.

10) Blanchet-Scalliet, C. and M. Jeanblanc, 2004, Hazard rate for credit risk and hedging defaultable contingent claims, Finance and Stochastics, Volume 8, Number 1, 145-159.

11) Coculescu, D., 2010, From the decomposition of a stopping time to risk premium decompositions, working paper.

12) Coculescu, D. and A. Nikeghbali, 2012, Hazard processes and martingale hazard processes, Mathematical Finance, Volume 22, Issue 3, 519-537.

13) Collin-Dufresne, P., Goldstein, R. and J. Hugonnier, 2004, A general formula for valuing defaultable securities, Econometrica, Vol. 72, N. 5, 1377-1407.

14) Committeri, M. and F. Spadafora, 2013, Your never give me your money? Sovereign debt crises, collective action problems, and IMF lending, IMF working paper.

15) Das, S. R. and P. Hanouna, Implied recovery, 2009, Journal of Economic Dynamics and Control, Volume 33 (11), 1837-1857.

16) Daves, P. R. and M. C. Ehrhardt, 1993, Liquidity, reconstitution, and the value of U.S. Treasury strips, The Journal of Finance, Volume 48, Issue 1, 315-329.

17) Duffie, D., 1998, Defaultable term structure models with fractional recovery of par, working paper, Stanford University.

18) Duffie, D., Schroder, M. and C. Skiadas, 1996, Recursive valuation of defaultable Securities and the timing of resolution of uncertainty, The Annals of Applied Probability, Volume 6, Issue 4, 1075-1090.

19) Duffie, D. and K. J Singleton, 1999, Modeling term structures of defaultable bonds, The Review of Financial Studies, Volume 12 (4), 687-720.

20) Duffie, D. and K. J. Singleton, Credit risk: Pricing, measurement, and management, Princeton University Press, 2003.

21) Elton E. J. and T. C. Green, 1998, Tax and liquidity effects in pricing government bonds, Journal of Finance, Volume 53 (5), 1533-1562.

22) Elliott, R. J., M. Jeanblanc and M. Yor, 2000, On models of default risk, Mathematical Finance, Volume 10, Issue 2, 179-196.

23) Finkelstein, V., 1999, The price of credit, Risk 12 (12).

24) François, P., G. Hübner, J-R. Sibille, 2011, A structural balance sheet model of sovereign credit risk, working paper, HEC Montréal.

25) Gibson, R. and S. M. Sundaresan, 1999, A model of sovereign borrowing and sovereign yield spreads, working paper.

26) Gray D. F., R. C. Merton and Z. Bodie, 2007, Contingent Claims Approach to Measuring and Managing Sovereign Credit Risk, Journal of Investment Management, vol. 5, 1-24.

27) Grinblatt, M. and F. Longstaff, 2000, Financial innovation and the role of derivative securities: An empirical analysis of the Treasury STRIPS program, The Journal of Finance, Volume 55, Issue 3, 1415-1436.

28) Guha, R., 2003, Recovery of face value at default: Empirical evidence and implications for credit risk pricing, working paper, London Business School.

29) Huij, J., M. Livingston and L. Svinkels, 2010, Is risk arbitrage compensated? Evidence from the European STRIPS market, working paper.

30) Jarrow, R. A., Lando, D. and S. M. Turnbull, 1997, A Markov model for the term structure of credit risk spreads, Review of Financial Studies, Volume 10 (2), 481-523 
31) Jarrow, R. A. and S. M. Turnbull, 1995, Pricing derivatives on financial securities subject to credit risk, The Journal of Finance, Volume 50 (1), 53-85.

32) Jeanneret, A., 2012, The dynamics of sovereign credit risk, working paper, HEC Montréal.

33) Jordan, B. D., R. D. Jorgensen and D. R. Kuipers, 2000, The relative pricing of U.S. Treasury STRIPS: Empirical evidence, Journal of Financial Economics, 56, 89-123.

34) Kikuchin, K. and K. Shintani, 2012, Comparative Analysis of Zero Coupon Yield Curve Estimation Methods Using JGB Price Data, IMES, Bank of Japan, Discussion Paper No. 2012-E-4

35) Lando, D., 1998, On Cox processes and credit risky securities, Review of Derivatives Research, 2, 99-120.

36) Lando, D., Credit risk modeling: Theory and applications, Princeton Series in Finance, Princeton University Press, 2004.

37) Lee, M., 2007, Bloomberg fair value market curves, Bloomberg.

38) Longstaff, F., J. Pan, L. Pedersen, and K. Singleton, 2011, How sovereign is sovereign credit risk? American Economic Journal: Macroeconomics 3 (2), 75-103.

39) Madan, D. B., G. Bakshi and F. X. Zhang, 2006, Understanding the role of recovery in default risk models: empirical comparisons and implied recovery rates, FDIC CFR working paper No. 6.

40) McCulloch, J. H., 1975, The Tax-adjusted yield curve, Journal of Finance, Volume 30 (3), 811-830.

41) Merrick, J. J., 2001, Crisis dynamics of implied default recovery ratios: evidence from Russia and Argentina, Journal of Banking \& Finance, Volume 25 (10), 1921-1939.

42) Nelson, C. R. and A. F. Siegel, 1987, Parsimonious modeling of yield curves, The Journal of Business, Vol. 60, N4, 473-489.

43) O’Kane, D. and S. Sen, 2005, Credit Spreads Explained, Journal of Credit Risk, Volume 1/Number 2, Spring 2005, 61-78.

44) Pan, J. and K. J. Singleton, 2008, Default and recovery implicit in the term structure of sovereign CDS spreads, Journal of Finance, Volume 63 (5), 2345-2384.

45) Schönbucher, P. J., 1998, Term structure modelling of defaultable bonds, Review of Derivatives Research, Volume 2 (2-3), 161-192.

46) Stein, H., 2012, Counterparty risk, CVA, and Basel III, Columbia University Financial Engineering Practitioners Seminar.

47) Vrugt, E. B., 2011, Estimating implied default probabilities and recovery values for sovereign bond prices, Journal of Fixed Income, Vol. 21, N. 2, 5-14.

48) Ward, W. J., 2010, Bloomberg's fixed income evaluated pricing service, Bloomberg.

49) Ward, W. J., 2011, Sovereign debt valuations, Bloomberg.

50) Yu, F., 2002, Modeling Expected Return on Defaultable Bonds, Journal of Fixed Income, 12(2): 69-81.

\footnotetext{
${ }^{\mathrm{i}}$ In this framework, default date is a totally inaccessible stopping time. Moreover, the compensator of the default indicator function is assumed to be absolutely continuous with respect to the Lebesgue measure. One may refer to $\lambda$ as a pre-default intensity. The fractional recovery of market value approach is coupled here with the reduced-form approach (see Jarrow and Turnbull [1995], Jarrow et al. [1997]). When considering stochastic models of default, we will remain in the above setting throughout the paper.

ii This risk-neutral measure is associated with the savings account numeraire. Existence of a defaultfree short rate is postulated.

iii See the articles by Duffie et al. [1996], Duffie and Singleton [1999] and Collin-Dufresne et al. [2004]. In this approach, the arrival of information, i.e. the market filtration is given and includes observation of default date. Similar results have been obtained in a slightly different setting by Elliott et al. [2000], Blanchet-Scalliet and Jeanblanc [2004], Bielecki et al. [2004] and the book by Bielecki
} 
and Rutkowski [2010]. In this the latter approach, the market filtration results from a progressive enlargement of a background filtration with the observation of default arrival. The above approaches are rather abstract and general. We refer to Coculescu and Nikeghbali [2012] for a comprehensive approach to discounting and default. One can think of using more restrictive but easier to grasp modelling, for instance Cox processes as in Lando [1998, 2004], Duffie and Singleton [2003]. Such a framework, thanks to the conditional independence of default time and state variables, guarantees that the basic technical assumptions of the general approaches are fulfilled. When dealing with fractional recovery of market value, there is an extra degree of mathematical involvement. The payment in case of default involves the pre-default price, resulting in a recursive valuation problem and the need to solve for an integral equation.

iv The reduced form or intensity approach is mostly used when sovereign default is considered. Alternatively, Gray and al. [2007], François et al. [2011], Jeanneret [2012] use a structural approach. Consequently, sovereign defaults are predictable. As a consequence of smooth pasting condition or of the probabilistic results in Coculescu [2010], there is no jump in defaultable bond prices at default. In that structural framework, we can still consider a recovery rate, since there is a cut-off in debt payments after strategic renegotiation with lenders. We refer to Gibson and Sundaresan [1999] for an early contribution in that area. The bond price dynamics are obviously different at default time under reduced form and structural approaches. Our cross-sectional and model-free point of view encompasses the two mainstream approaches. 